\title{
Un nuevo agente en los mecanismos de la adicción al alcohol y la ingesta: el núcleo incertus y el neuropéptido relaxina-3
}

\author{
José A. Nova-Marqués, Cristina García-Díaz, Francisco E. Olucha-Bordonau
}

Resumen. La ingesta de alcohol está facilitada por la relación con la conducta alimentaria, y ambas conductas están altamente influidas por situaciones de estrés y ansiedad. La desregulación de estos procesos puede llegar a situaciones patológicas, como la anorexia, la bulimia o la obesidad. Los elementos neurobiológicos que subyacen a este control no están completamente esclarecidos. El núcleo incertus (NI) en el tegmento pontino constituye un elemento común a la ingesta y a la adicción al alcohol. Las neuronas del NI utilizan como señalización el neuropéptido relaxina-3 (RLN3) y su receptor RXFP3. En esta revisión se analiza la participación del sistema NI-RLN3-RXFP3 en estas conductas bajo condiciones de ansiedad o estrés en modelos animales. La activación del NI tiene un efecto positivo sobre la ingesta (orexígeno) y desarrolla una respuesta amplia en la amígdala, donde se modulan los estados de ansiedad. La actividad de RLN3-RXFP3 en la amígdala podría afectar a la adicción al alcohol, ya que la aplicación del antagonista de RXFP3 en la amígdala extendida atenúa la recaída al alcohol inducida por el estrés. Los datos neuroanatómicos indican que el sistema NI-RLN3-RXFP3 actúa sobre la conducta de ingesta y adicción al alcohol mediante proyecciones paralelas a las vías canónicas mesolímbicas. Con ello, los datos en modelos animales indican que el sistema NI-RLN3-RXFP3 debería tenerse en cuenta como diana en el tratamiento futuro de trastornos de las conductas alimentarias y adictivas.

Palabras clave. Alcoholismo. Anorexia. Ansiedad. Arousal. Bulimia. Estrés.

\section{Introducción}

La enfermedad adictiva se puede definir como una patología del sistema nervioso central debida a una disfunción neurobiológica de estructuras cerebrales mesencefálicas, límbicas y corticales, y de circuitos cerebrales implicados en la motivación y la conducta. La adicción a sustancias psicoactivas se presenta en múltiples formas conductuales, que evolucionan con un agravamiento progresivo de la enfermedad y un mal pronóstico [1]. Una de las adicciones que más impacto causa a la sociedad actual es la dependencia a sustancias psicoactivas o adicción a drogas [2]. Cuando estas drogas se consumen en exceso, producen una activación directa del sistema implicado en el sistema de recompensa, cuyo sustrato anatómico es la vía mesolímbica que se origina en el área ventral tegmentaria (VTA) y se proyecta hacia el núcleo accumbens, y diferentes áreas corticales, que incluyen la corteza cingulada anterior, la corteza orbitofrontal y la corteza prefrontal [3]. Los efectos comportamentales se muestran en las recaídas y en el deseo intenso de consumo (craving) cuando la persona se expone a estímulos relacionados con la droga. La dependencia cursa también con un deterioro de la capacidad de autocontrol sobre el consumo de la sustancia. Los individuos con menores niveles de autocontrol reflejan disfunciones en los mecanismos de inhibición cerebral, entre los que está fuertemente implicada la corteza prefrontal, y están, en consecuencia, más predispuestos a desarrollar trastornos por consumo de sustancias. Es importante destacar que, al activar el circuito de recompensa cerebral, las sustancias psicoactivas utilizan los mismos mecanismos fisiológicos que los reforzantes naturales (agua, comida y conducta sexual) [4].

Desde el punto de vista psicológico y psiquiátrico, las adicciones asocian o incluyen una serie de trastornos, como ansiedad, depresión, pensamientos obsesivos, aislamiento, trastornos afectivos, trastornos en las relaciones sociales, problemas escolares, como fracaso escolar, dificultades ocupacionales o interpersonales, aislamiento, negligencia en las responsabilidades sociales o personales e inquietud mental o física [5]. En los casos en los que el individuo reduce o detiene un comportamiento adictivo específico, se produce una fatiga excesiva, cambios en el estilo de vida, reducción significativa de la actividad física, privación y cambios en los patrones de sueño, impaciencia, violencia, trastornos alimentarios y síntomas de abstinencia.
Unidad Predepartamental de Medicina. Facultad de Ciencias de la Salud. Universitat Jaume I. Castellón de la Plana, España.

Correspondencia:

Dr. Francisco E. Olucha Bordonau. Unidad Predepartamental de Medicina. Facultad de Ciencias de la Salud. Universitat Jaume I. Avda. Vicent Sos Baynat, s/n. E-12071 Castellón de la Plana.

E-mail:

folucha@uji.es

Financiación:

Universitat Jaume I, grant UJB2016-40 (FEO-B). Esta revisión forma parte del trabajo de fin de grado de J.A.N.M.

Aceptado tras revisión externa: 12.06.18.

Cómo citar este artículo: Nova-Marqués JA, García-Díaz C, Olucha-Bordonau FE. Un nuevo agente en los mecanismos de la adicción al alcohol y la ingesta: el núcleo incertus y el neuropéptido relaxina-3. Rev Neurol 2018; 67: 175-86.

(c) 2018 Revista de Neurología 
El alcohol altera la actividad de moléculas de señalización y su consumo prolongado desregula profundamente circuitos neuroquímicos clave en el sistema de recompensa (dopamina, endocannabinoides) y en la respuesta del sistema nervioso central al estrés -factor liberador de corticotropina (CRF) e ingesta, neuropéptido Y- [6]. En un modelo de rata de abuso de alcohol se demostró que la administración de un antagonista para el receptor del neuropéptido relaxina-3 (RLN3) disminuía tanto la autoadministración de alcohol como la inducción de estrés secundaria a la falta de alcohol [7]. El núcleo incertus (NI) en el tegmento pontino es la principal estructura cerebral que produce y libera relaxina-3 (RLN3) [8,9]. RXFP3 es el receptor natural de RLN3. RXFP3 es un receptor acoplado a la proteína $\mathrm{G}$ que lleva una unidad $\alpha_{\mathrm{i} / \mathrm{o}}$ que activa la degradación del monofosfato de adenosina cíclico y promociona la fosforilación de ERK [10].

Los trastornos de la conducta alimentaria y de la ingesta de alimentos se caracterizan por una alteración persistente en la alimentación o en el comportamiento relacionado con la alimentación que lleva a una alteración en el consumo de alimentos y que causa un deterioro significativo de la salud física o del funcionamiento psicosocial [11]. Algunos individuos con trastornos de la conducta alimentaria refieren síntomas similares a los que suelen atribuirse a las personas con trastornos por consumo de sustancias, como el ansia y los patrones de consumo compulsivo [11]. Esta semejanza puede reflejar la implicación de los mismos sistemas neuronales, como los relacionados con la regulación del autocontrol y la recompensa, en los dos grupos de trastornos. Actualmente, múltiples estudios relacionan procesos como el estrés y la ingesta alimentaria con el NI, dada la actividad orexígena de RLN3 y su relación con otros neuropéptidos con función orexígena (orexina) o anorexígena (CRF) [12]. Además, existen múltiples patologías (bulimia, anorexia) que muestran una relación inequívoca entre estrés e ingesta alimentaria compulsiva y desestructurada [13]. Hay estudios que evidencian la mediación del RLN3 en el incremento de la ingesta mediado por estrés [14]. Un aspecto de relevancia clínica es la observación de polimorfismos asociados con los genes de RLN3 y de su receptor RXFP3 en pacientes con enfermedades mentales que desarrollan síndromes metabólicos asociados a la medicación con antipsicóticos [15].

Por todo ello, esta revisión pretende poner en común los diferentes descubrimientos que evidencian la probable implicación del NI y su sistema de señalización RLN3/RXFP3 en múltiples procesos neurobiológicos, desbrozando su implicación en el sustrato fisiopatológico de la adicción y los trastornos de la conducta alimentaria.

Muchos de los circuitos neuronales involucrados en la mediación de comportamientos y trastornos complejos, como ansiedad, depresión, adicción y comportamientos sociales disfuncionales, implican la activación de la amígdala en conjunción con circuitos corticales y del hipocampo. Las proyecciones subcorticales ascendentes proporcionan entradas moduladoras a la amígdala. Uno de estos aportes se origina en el NI, cuya señalización mediante RLN3 se ha implicado en la modulación de la recompensa/ motivación y la ansiedad y comportamientos depresivos en los roedores a través de acciones dentro de la amígdala [16]. Se ha demostrado la existencia de proyecciones topográficas del NI que contienen proyecciones a núcleos específicos de la amígdala, en consonancia con un papel probable para este sistema de excitación integrador putativo en la regulación de los comportamientos sociales y emocionales dependientes de la amígdala [16].

Las vías neurales que manejan información ejecutiva sobre el grado de consciencia (arousal) en el cerebro están asociadas con la modulación del comportamiento de acuerdo con los requerimientos ambientales, y el punto clave en esta regulación es el área septal [17]. Estudios de definición de vías neurales de la rata han demostrado que el área septal es diana de proyecciones ascendentes desde el NI [18]. El NI en la rata presenta una fuerte expresión de $\mathrm{CRF}_{1}$; de hecho, en la rata, las neuronas RLN3-positivas coexpresan $C_{1} F_{1}$, aunque no constituyan el total de la población neuronal $\mathrm{CRF}_{1}$-positiva [19]. Por tanto, el NI se postula como un agente que facilita la respuesta al estrés activando la capacidad del área septal para activar el nivel de consciencia y actividad. De hecho, la activación específica del NI provoca un aumento en el nivel de actividad cortical, pasando a un electroencefalograma activo, y activa las conductas de vigilancia en un paradigma de miedo condicionado [20]. Hay que tener presente que la activación de los mecanismos de arousal es uno de los aspectos relevantes de la conducta adictiva, en el sentido de que las conductas van dirigidas casi exclusivamente a la consecución de la conducta adictiva, y es la abstinencia la que induce el mecanismo de arousal [21].

\section{Sistema NI-RLN3}

RLN3 es un péptido de las familias de relaxinas e insulinas. Aunque se conoce una limitada expresión 
periférica de RLN3 [22], el principal lugar de expresión de RLN3 es el sistema nervioso central, donde se ha detectado en múltiples especies, incluyendo el pez cebra [23], el ratón [24], la rata [25], el macaco [8] y el ser humano [26]. La expresión del ARNm de RLN3 se limita a un pequeño número de neuronas en el NI, pero con un extenso patrón de proyecciones ascendentes sobre el mesencéfalo y el telencéfalo con una distribución similar en todas las especies estudiadas $[27,28]$. Además, se han detectado unas pocas neuronas que expresan RLN3 en el rafe pontino, la parte ventral de la sustancia gris del acueducto y la división lateral de la sustancia negra $[8,9]$. Debido a que la rata y el ratón son las principales especies 'experimentales', su patrón de expresión de RLN3 es el más estudiado. Existe una fuerte correlación entre las áreas que expresan el ARNm del receptor de RLN3, RXFP3 y las áreas que contienen el péptido RLN3. Además, la localización de RLN3 parece conservarse evolutivamente, como se observa en el pez cebra [29].

El NI fue descrito como una región en la línea media del suelo del cuarto ventrículo, un grupo celular en las regiones centrocaudales de la sustancia gris periventricular pontina, adyacente al borde ventromedial del núcleo tegmentario dorsal caudal [27, 28]. Sin embargo, en los últimos años han surgido nuevas evidencias que señalan el papel que desempeña el NI en múltiples procesos cerebrales, como la respuesta de estrés [30], la memoria [31-33] y la emoción [34].

Tras la localización de RLN3 en el NI, estudios inmunohistoquímicos confirman que las neuronas RLN3-positivas son neuronas gabérgicas -reflejadas por su coexpresión de GAD, la enzima sintetizadora del ácido $\gamma$-aminobutírico (GABA)- [28], es decir, que el NI contiene el neurotransmisor inhibitorio del GABA, aunque el NI comprende un grupo distinto de neuronas gabérgicas que tienen prominentes proyecciones más largas. Estudios anatómicos detallados confirman que estas neuronas gabérgicas del NI tienen proyecciones dispersas sobre el mesencéfalo, el diencéfalo y el telencéfalo [28]. Las neuronas del NI no parecen producir niveles significativos de marcadores para la transmisión de aminoácidos excitatorios, lo que sugiere que el papel principal de las neuronas del NI en la neurotransmisión es inhibitorio [7].

En las neuronas del NI se expresan varios neuropéptidos, incluyendo RLN3, neuromedina B, colecistocinina, calbindina y calretinina (proteínas ligadoras de calcio, normalmente colocalizadas con GABA), pero RLN3 es el más restringido al área [28]. Sobre esta base, se argumenta que el estudio de las funciones de RLN3 y sus interacciones con la transmisión de GABA debe proporcionar importantes conocimientos sobre las funciones del NI.

El receptor para RLN3 es el del péptido 3 de la familia de RLN3 (RXFP3), un receptor acoplado a la proteína $\mathrm{G}$ que se acopla a proteínas $\mathrm{G}_{\mathrm{i} / \mathrm{o}}$ inhibidoras. Estudios in vitro que utilizaron células no neuronales que sobreexpresan RXFP3 han demostrado que se acopla a las proteínas $\mathrm{G}$ inhibidoras e inhibe la acumulación de monofosfato de adenosina cíclico [22]. También se conoce como receptor acoplado a proteína G 135 (GPCR135) [22]. RXFP3 muestra una alta afinidad por RLN3, RLN3 es el único miembro de la superfamilia de relaxinas que puede activar RXFP3, y los genes que codifican ambas proteínas parecen haber coevolucionado filogenéticamente entre sí [22].

RXFP3 se expresa en varias regiones cerebrales relacionadas con el estrés, incluyendo el núcleo paraventricular, donde podría regular el CRF y la vasopresina/oxitocina, reguladores críticos del eje del estrés en diferentes condiciones fisiológicas [35]. La expresión de RLN3 se incrementa en las neuronas del NI por estrés neurógeno, como se ha observado en ratas al someterlas al test de natación forzada, estrés social, ejercicio en cinta ergométrica y estrés por inmovilización, situaciones que estimulan fisiológicamente la excitación y el estado de alerta [30].

Las neuronas RLN3-positivas del NI de la rata expresan receptores de CRF de tipo 1 (CRF-R1) [36] y responden con aumento de c-Fos a la inyección de CRF intracerebroventricular o a diferentes factores de estrés fisiológicos, como se ha comentado [9, 30]. Las neuronas RLN3-positivas del NI de la rata también expresan receptores de orexina/hipocretina de tipo 1 y 2 , y receptores de la hormona concentradora de melanina de tipo $1\left(\mathrm{MCH}_{1}\right)$ con función orexígena [37].

Las principales aferencias (inputs) del NI provienen de la corteza prefrontal medial, la corteza orbitofrontal, el septo medial, la banda diagonal, el núcleo septofimbrial, la parte medial de la habénula lateral, el núcleo preóptico ventrolateral, el núcleo supramamilar, el polo caudal del núcleo parafascicular del tálamo, el núcleo periacueductal, el núcleo interpeduncular, el núcleo medial del rafe, el extremo caudal del núcleo dorsal del rafe, el núcleo prepósito y el NI contralateral [27].

Las principales eferencias (outputs) del NI van hacia la corteza prefrontal, el hipocampo, el núcleo septal medial, el núcleo de la banda diagonal, la amígdala (núcleos basolateral, cortical y medial, y el área amigdalohipocámpica), el núcleo del lecho de la estría terminal, el núcleo dorsomedial del tálamo, 
Figura 1. Interferencia del núcleo incertus (NI) sobre el sistema Hb-tVTA-VTA. El área ventral tegmentaria (VTA) envía proyecciones dopaminérgicas al núcleo accumbens (NA) y produce una estimulación de éste frente a un estímulo de recompensa, y el NA, a su vez, proyecta a la corteza prefrontal, vía de la recompensa. La amígdala recibe proyecciones dopaminérgicas del VTA y proyecta sobre el NA (modulación de los estímulos condicionados). La habénula $(\mathrm{Hb})$ envía proyecciones glutamatérgicas para estimular el núcleo inhibitorio del VTA (tVTA) frente a un estímulo aversivo, y el tVTA envía proyecciones gabérgicas inhibitorias al VTA (esta situación confecciona la vía de la aversión). Además, existen unas pocas proyecciones de la $\mathrm{Hb}$ al VTA (modulación de la actividad de la corteza prefrontal para impulsar la aversión). El $\mathrm{NI}$ presenta proyecciones unidireccionales con la corteza prefrontal y el tVTA, y con la Hb presenta un patrón recíproco de proyecciones hacia y desde la división medial de la Hb lateral.

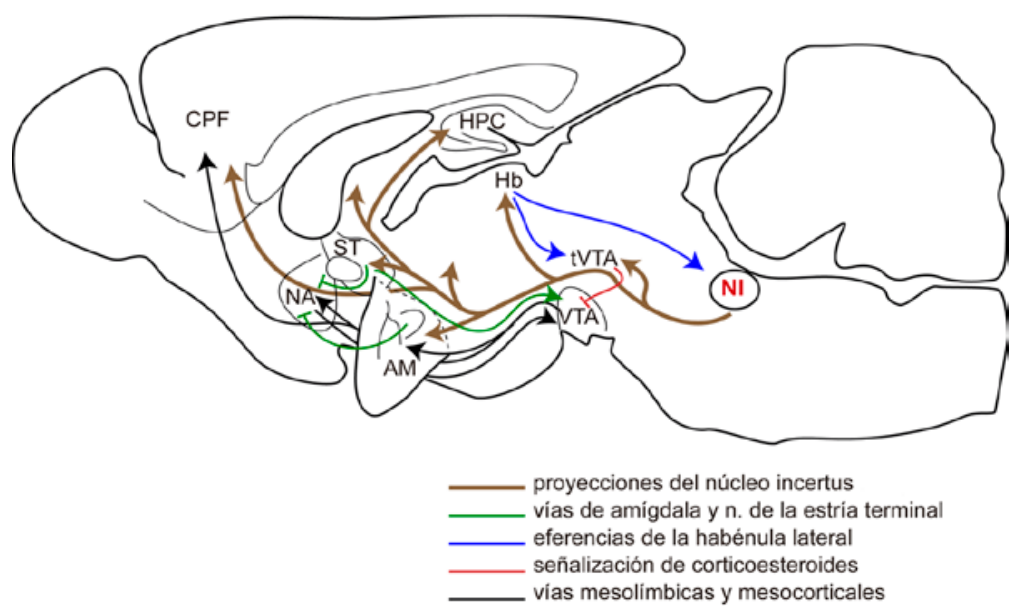

el núcleo supraquiasmático, el área preóptica lateral, el hipotálamo lateral y posterior, el núcleo mamilar lateral, el núcleo supramamilar, el VTA, el colículo superior (o tectum), el núcleo interpeduncular, el núcleo medial del rafe, el núcleo tegmentario laterodorsal, las cápsulas que rodean los núcleos tegmentarios dorsal y ventral, el núcleo dorsal del rafe, el núcleo prepósito y el núcleo accesorio de la oliva inferior [27,28].

La corteza prefrontal medial desempeña un papel principal en la modulación de las funciones cognitivas (sobre todo, la memoria de trabajo y la flexibilidad cognitiva), mientras que la corteza cingulada anterior es imprescindible en la modulación de la memoria del miedo (procesamiento del miedo, del dolor y de los estímulos de amenaza), y ambas estructuras son muy sensibles al estrés [38]. Ciertos estudios revelan que la estimulación del NI (tanto eléctrica como por infusión de CRF) disminuye la actividad de la corteza prefrontal medial, pero aumenta la de la corteza cingulada anterior [38]. Tanto la corteza prefrontal como la corteza cingulada anterior forman parte del sistema de recompensa cerebral.

Cabe destacar que muchas de las conexiones del NI proyectan a través del haz medial prosencefálico medial, como las conexiones entre el NI y la amígdala y el núcleo supraquiasmático [28].

\section{Vías de recompensa y adicción}

Estudios experimentales sobre roedores han puesto de manifiesto que la administración aguda de psicoestimulantes, alcohol y opiáceos provoca un incremento en la actividad del sistema dopaminérgico de la recompensa [39]. En este sentido, las sustancias adictivas se comportan de manera similar a las recompensas naturales (la bebida, el sexo o las relaciones sociales); sin embargo, a diferencia de éstas, las sustancias adictivas inducen sensibilización dopaminérgica, sobre todo cuando se consumen de forma repetida e intermitente [40].

El consumo crónico de sustancias adictivas favorece el desarrollo de cambios neuroadaptativos que afectan a distintos niveles del sistema dopaminérgico. La sensibilización inducida por el consumo crónico de drogas, en especial por los psicoestimulantes, regula al alza la expresión de los receptores D1 durante los primeros días de abstinencia, e implica tanto al núcleo accumbens como al estriado dorsal. Se ha asociado también un aumento de la respuesta de los receptores D1, que persiste durante un mes después del inicio de la abstinencia [41]. Por otro lado, se ha descrito una regulación a la baja de los receptores D2. Se ha relacionado un subtipo de receptores de la familia D2, los receptores D3, con la sensibilización dopaminérgica asociada a la administración repetida de estimulantes [42].

La corteza prefrontal está implicada en los aspectos motivacionales de la conducta dirigida a objetivos y su alteración funcional puede explicar, en parte, la conducta compulsiva de búsqueda de droga que caracteriza la adicción. El predominio de la actividad D1 favorece un estado inhibitorio en el que sólo los estímulos más fuertes pueden provocar activación y motivar la conducta. En estas condiciones, en pacientes adictos, sólo la droga y los estímulos asociados a ella (y no los reforzantes naturales) son suficientemente fuertes como para provocar la liberación de la dopamina necesaria para activar la corteza prefrontal y sobrepasar la inhibición producida por el predominio de la activación de los receptores D1 [43]. La actividad de la corteza prefrontal está modulada en gran medida por el NI. De hecho, es posible provocar cambios de potenciación a largo plazo en la corteza prefrontal mediante estímulos de alta frecuencia desde el hipocampo; así, la lesión del NI elimina esa capacidad de formar cambios a largo plazo en la corteza prefrontal [44]. 
Una estructura que está recibiendo gran consideración en conductas adictivas es la habénula (Fig. 1). Esta estructura epitalámica se ha relacionado con el procesamiento de recompensas, así como con la regulación del afecto y los comportamientos dirigidos a metas [45]. Se ha demostrado que la división lateral de la habénula ( $\mathrm{HbL}$ ) está involucrada en funciones como la recompensa, la aversión, la cognición, el comportamiento materno, el sueño y los ritmos circadianos, y su disfunción se ha relacionado con procesos patológicos como la adicción, la depresión y la esquizofrenia [46].

Las neuronas de la $\mathrm{HbL}$, que son principalmente glutamatérgicas, se activan mediante señales de aversión, una acción sin recompensa o un error de predicción (es decir, una ausencia de recompensa esperada), y se inhiben por una recompensa esperada o inesperada [47]. Curiosamente, las neuronas dopaminérgicas del VTA se comportan al revés en presencia de una recompensa o un estímulo aversivo. Las proyecciones glutamatérgicas de la $\mathrm{HbL}$ terminan sobre todo en la cola del VTA (tVTA, también llamado núcleo tegmentario rostromedial), que es un núcleo gabérgico que inhibe el VTA. Por lo tanto, el circuito HbL-tVTA-VTA predice resultados tanto apetitivos como aversivos (Fig. 1). Los animales con ablación de la $\mathrm{HbL}$ no extinguen el comportamiento de búsqueda de drogas; además, la ingesta de cocaína no se ve afectada, lo que sugiere que los animales no son capaces de disminuir la búsqueda de drogas incluso si no hay efectos más gratificantes. Por otro lado, el consumo voluntario de etanol es mayor en las ratas con lesiones de la HbL que en los animales control simulados [48]. Esto demuestra el importante papel de la $\mathrm{HbL}$ en la regulación de los comportamientos dirigidos por drogas y en la mediación de los efectos de la ingesta de drogas.

El circuito entre la HbL y el NI puede desempeñar un papel central en la modulación de la actividad de la HbL relacionada con la ingesta de drogas. Específicamente, la división medial de la HbL mantiene conexiones recíprocas con el NI. Dado que el NI proyecta al tVTA, la acción de la HbL sobre el tVTA podría ser directa y también indirecta a través del NI (Fig. 1) [27].

\section{Implicación del núcleo incertus en los procesos de arousal, ansiedad y estrés}

Si bien hay una relación entre los procesos de arousal, ansiedad y estrés, existen matices diferenciales y son soportados por sustratos anatómicos diferen-
Figura 2. Interferencia del núcleo incertus (NI) sobre los sistemas de control de la ansiedad y el estrés. El $\mathrm{NI}$ es sensible a los mecanismos de estrés mediados por el factor liberador de corticotropina (CRF). Desde el NI se extienden las proyecciones sobre centros del prosencéfalo implicados en la conducta adictiva al alcohol, como el núcleo de la estría terminal, o sobre centros de control del estado de ansiedad, como la amígdala. La activación de la respuesta de estrés a través del eje hipotálamo (CRF)-hipófiso (hormona adrenocorticotropa)-adrenal (corticoesteroides, COR) origina una serie de respuestas de movilización de recursos en los órganos periféricos y un control negativo sobre los órganos del sistema nervioso central responsables de la respuesta de estrés en el eje. La acción del NI puede modular la capacidad de respuesta en todos estos centros.

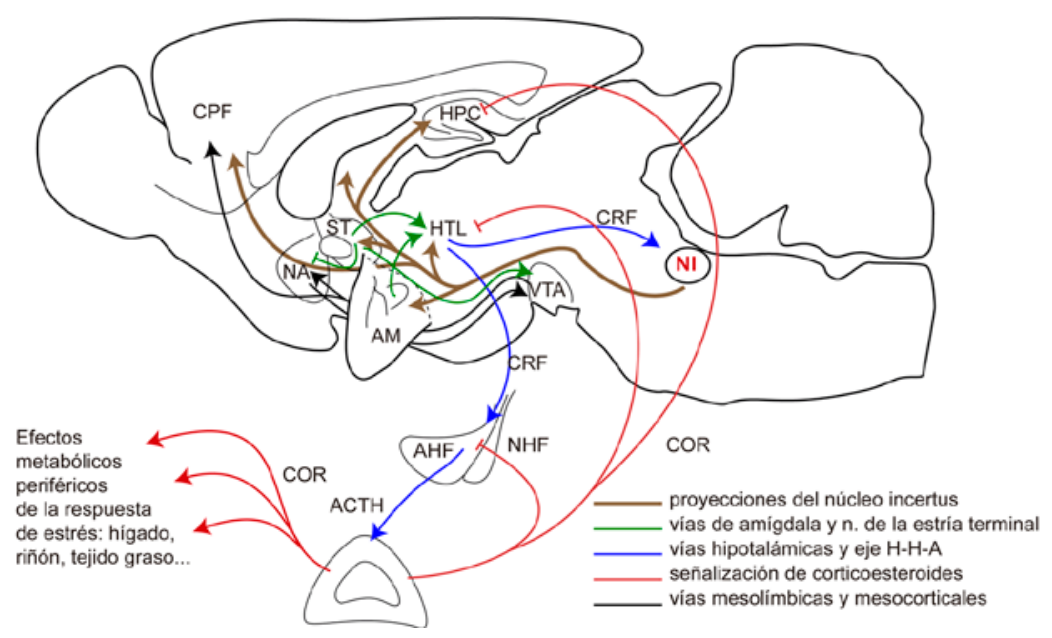

tes, pero los tres están modulados en parte por el NI y el sistema de señalización RLN3/RXFP3 [9].

El NI proyecta a muchas áreas cerebrales asociadas con el estado de alerta a los estímulos sensoriales, la actividad motora y la reactividad emocional (arousal) [27,28]. Estudios recientes proporcionan evidencia de que el NI puede modular los niveles de consciencia [38]. Se ha observado en roedores nocturnos que la expresión de ARNm de RLN3 en el NI varía durante el ciclo de 24 horas, con un pico a las 20:00 horas (durante la fase oscura/activa) y una disminución a las 08:00 horas (durante la fase de luz/inactiva) [49]. Estos datos son consistentes con la idea de que las neuronas del NI y el RLN3 están más activas durante la fase activa (o arousal) del ciclo luz/oscuridad.

Por otro lado, se considera estrés la manifestación fisiológica asociada al sobreesfuerzo impuesto al funcionamiento normal de un individuo y que sobrepasa sus recursos [13]. La situación de estrés implica la activación del eje hipotalámico hipofisario mediado por CRF y hormona adrenocorticotropa (Fig. 2). Adicionalmente, el CRF también es liberado centralmente y, como consecuencia, se activan una serie de vías centrales que hacen que la respuesta de estrés, además de hormonal, sea neural 
[50]. El NI se ha propuesto como uno de los centros neurales que, debido a la alta concentración de receptores CRF-R1, podrían mediar en la respuesta de estrés [9]. También se ha observado que diversas formas de estrés, como la natación forzada, son capaces de activar específicamente el NI [30]. La adición de CRF a un cultivo ex vivo de secciones del NI provoca un aumento del nivel de disparos, específicamente en las neuronas RLN3 positivas del núcleo, pero no en las RLN3 negativas [36]. La interacción entre el nivel de estrés, la conducta alimentaria y el arousal viene determinada por el hecho de que estas mismas neuronas responden a agonistas del neuropéptido orexina [51].

La ansiedad implica una combinación de emociones de afecto negativo y síntomas somáticos de tensión en los que el sujeto anticipa un acontecimiento negativo o peligroso [13]. El sustrato anatómico de la ansiedad es la amígdala, donde se ponen en marcha sistemas de anticipación a acontecimientos de carácter negativo [52]. El papel del NI en los procesos de ansiedad presenta un cierto aspecto controvertido, mientras que ratones mutantes knockout para RLN3 estaban menos tiempo en los brazos abiertos del laberinto en cruz elevado, lo que indicaría un carácter ansiógeno a RLN3 [53]; la inyección intracerebroventricular del agonista de RLN3 también provoca un mayor tiempo en los brazos abiertos, lo que indicaría un efecto ansiolítico [54]. Por otra parte, la buspirona es un ansiolítico que es un agonista parcial del receptor $5-\mathrm{HT}_{1 \mathrm{~A}} \mathrm{y}$ un antagonista de los receptores D2. Varios estudios preclínicos han informado de un efecto bifásico de modulación de la ansiedad de la buspirona. El efecto ansiógeno se ha reproducido en un estudio mediante la infusión directa de buspirona en el NI, pero se abolió en las ratas con lesión de tipo NI-CRF-saporina, lo que indica que el NI está presente en los circuitos neuronales que conducen el comportamiento ansiógeno [55]. Esto lleva a la conclusión de que $5-\mathrm{HT}_{1 \mathrm{~A}}$ en el NI contribuye al efecto ansiógeno de una dosis elevada aguda de buspirona en ratas y puede ser funcionalmente relevante para la ansiedad fisiológica.

Existe un cierto consenso acerca de la intersección de los procesos de ansiedad, estrés y desregulación en los niveles de consciencia (arousal) con diversas conductas adictivas al alcohol o a procesos de desregulación de la conducta alimentaria [56]. Uno de los efectos de la inyección intracerebroventricular del antagonista de RXFP3 es la atenuación del efecto de la recaída inducida por el estrés tras la extinción de la conducta adictiva al alcohol [7]. También se ha observado que el efecto de la ansie- dad sobre el consumo de alcohol puede estar mediado por la señalización RLN3-RXFP3. En ratas en las que la droga ansiógena yohimbina provocaba la recaída en el consumo de alcohol, la inyección de un antagonista de RLN3 en la amígdala central produjo una atenuación de la recaída en el consumo de alcohol inducido por la yohimbina [57]. Este efecto conjunto también se ha observado en un modelo de atracón inducido por estrés, donde los animales eran separados en dos grupos: uno en el cual footshocks de estrés impredecibles eran capaces de inducir el atracón de azúcar (binge prone), y otro en el cual los footshocks eran incapaces de inducir el atracón (binge resistant). En este modelo, la inyección intracerebroventricular de un antagonista de RLN3 bloqueó el consumo de azúcar como respuesta a shocks impredecibles en las ratas hembras binge prone [14]. Estos datos indican que el sistema NIRLN3-RXFP3 podría ser uno de los elementos de esa intersección, ya que ha quedado probada su participación conjunta en esos procesos.

\section{Conducta alimentaria como modelo comparativo a la enfermedad adictiva}

La conducta alimentaria en realidad sigue un modelo adictivo, en el cual la ausencia de metabolitos circulantes resultado de la digestión ocasiona un estado de búsqueda que induce a una nueva ingesta, a la cual seguirá un estado de saciedad que concluirá cuando se produzca un nuevo estado de desabastecimiento. La desregulación de este sistema produce trastornos alimentarios que llevan a la obesidad o a la anorexia [58].

La ingesta compulsiva se encuentra frecuentemente estimulada por el estrés [12]. El sistema RLN3/RXFP3 está implicado en respuestas neurobiológicas al estrés, así como a las conductas alimentarias [59]. Los neuropéptidos CRF y RLN3 producen efectos opuestos sobre la alimentación (anorexígeno y orexígeno, respectivamente). Asumiendo que el sistema de recompensa natural forma parte de la base conductual de la alimentación, se puede sugerir la relación del NI con las conductas adictivas, que utilizan esta vía de recompensa dopaminérgica. Para ello, se puede tomar como modelo de estudio la ingesta compulsiva, que afecta al $4,5 \%$ de la población general y es un síntoma básico en los trastornos por atracón, la bulimia nerviosa y el subtipo purga de la anorexia nerviosa [13]. La ingesta compulsiva se caracteriza por el consumo excesivo de alimentos en un breve período en el cual uno no se siente hambriento. Se ha observado la im- 
plicación del sistema NI/RLN3 en la ingesta compulsiva mediada por el estrés [14].

Se han investigado los efectos específicos para cada sexo en cuanto a situaciones de estrés repetido y restricción en la ingesta de alimentos, así como el peso corporal, los niveles plasmáticos de corticosterona y la expresión de CRF en el hipotálamo y de RLN3 en el NI [60]. El estrés crónico y la restricción alimentaria repetida aumentan la ganancia de peso corporal en las ratas hembra, pero no en las ratas macho. Las ratas hembra con restricciones crónicas de alimento muestran una hiperproducción de corticosterona plasmática y una hipoproducción de CRF en el núcleo paraventricular. Además, las ratas hembra con una restricción alimentaria crónica expresan niveles más altos de RLN3 en el NI y de CRF en la región medial del área preóptica del hipotálamo. El desequilibrio central en la menor producción del neuropéptido anorexígeno CRF en el núcleo paraventricular y una mayor producción de RLN3 orexígena en el NI pueden favorecer una ingesta excesiva y el aumento de peso corporal en las ratas hembra con restricciones alimentarias crónicamente estresadas. Por ello, RLN3 tiene un efecto específico para cada sexo en la ingesta de alimentos y la regulación del peso corporal. Mientras que RLN3 aumenta la ingesta de alimentos y el peso corporal tanto en los machos como en las hembras, las ratas hembras son más sensibles a los efectos de RLN3 y muestran una estimulación más fuerte de la alimentación y una mayor ganancia de peso corporal en respuesta a la administración de RLN3 [61]. El acceso intermitente a alimentos sabrosos (que actuarían como sustancia de recompensa) puede inducir una ingesta compulsiva en roedores en condiciones no estresantes. Se ha observado que la alimentación compulsiva inducida por el estrés puede depender de los efectos sobre CRF-R1 y la señalización de orexina [12].

También se ha estudiado la regulación de RLN3 y RXFP3 en el cerebro de ratas de obesidad inducida por la dieta. Algunas ratas sometidas a dietas de alto índice calórico desarrollan obesidad, mientras que otras, a pesar de estar sometidas a la misma dieta, no la desarrollan. En estos casos se observó una expresión significativamente diferente del receptor en la amígdala y el hipotálamo del receptor RXFP3 en ratas con obesidad inducida por la dieta y resistentes a la dieta [62]. Hay asociaciones importantes entre la obesidad y ciertos trastornos mentales (trastorno de atracones, trastornos depresivo y bipolar, y esquizofrenia) [13]. Se ha visto que la expresión de ARNm de RLN3 en el NI es mayor en las ratas obesas inducidas por la dieta en compa- ración con las ratas de fenotipo resistente a la obesidad. La expresión más fuerte de RLN3 se acompaña de una disminución de la expresión de ARNm de RXFP3 en las ratas obesidad inducida por la dieta. Por otro lado, la privación de alimentos aumenta los niveles de expresión de RLN3 en el NI en las ratas con fenotipo resistente a la dieta, pero no afecta a la expresión de RLN3 en las ratas con obesidad inducida por la dieta. La reintroducción de alimento aumenta rápidamente la expresión de RXFP3 en las ratas obesas a los niveles observados en el fenotipo resistente. Estos resultados proporcionan evidencia de que la realimentación después de la privación de alimento puede aumentar los efectos orexígenos de la RLN3 en ratas con obesidad inducida por la dieta mediante la rápida regulación positiva de la expresión del receptor RXFP3 de RLN3 en regiones específicas del cerebro implicadas en la regulación de la ingesta de alimentos. Un incremento constitutivo de la expresión de RLN3 en el NI y un aumento de la expresión de RXFP3 en regiones cerebrales específicas pueden estar implicados en el aumento de la ingesta de alimentos [62].

\section{Alcohol y núcleo incertus en el estudio de las conductas adictivas}

Del mismo modo que los sistemas CRF y RLN3 parecen tener papeles complementarios en el comportamiento alimentario, tal complementariedad o interrelación podría producirse sobre los sistemas afectados por la ingesta abusiva de alcohol (Tabla). La exposición crónica al alcohol y otras drogas evoca muchos cambios neuroadaptivos en el cerebro. Dichos cambios incluyen la regulación positiva y negativa de los neuropéptidos y sus receptores. Entre ellos se encuentran los cambios en la modulación de las funciones relacionadas con el estrés, incluyendo el CRF, las urocortinas (1-3) y sus receptores afines $\left(\mathrm{CRF}_{1}\right.$ y $\left.\mathrm{CRF}_{2}\right)$ [63]. Se ha propuesto que un reclutamiento de mecanismos de CRF/urocortina (proteína anorexígena que pertenece a la familia de los factores liberadores de corticotropina y que se relaciona estructuralmente con el CRF) es más prominente en individuos con mayor sensibilidad o vulnerabilidad para los efectos inducidos por el alcohol [64]. Tras una exposición crónica al alcohol, las ratas presentan actividad hiperactiva extrahipotalámica de CRF. Consistentemente, el aumento de la búsqueda de alcohol y la ingesta pueden atenuarse tras la administración de antagonistas de $\mathrm{CRF}_{1}$, particularmente en animales con antecedentes de alcohol [65]. Los hallazgos actuales confirman estu- 
Tabla. Resumen de los modelos experimentales que relacionan la actividad del sistema NI-RLN3-RXFP3 con la ingesta de alcohol, la adicción, la ansiedad y el estrés.

\begin{tabular}{|c|c|c|}
\hline & Modelo experimental & Efecto de RLN3 \\
\hline $\begin{array}{l}\text { Kastman } \\
\text { et al }[76]\end{array}$ & $\begin{array}{l}\text { Inyección bilateral en el } \mathrm{NI} \text { de un } \\
\text { antagonista de los receptores } \mathrm{OX}_{1} \text { y } \mathrm{OX}_{2} \\
\text { para evaluar el restablecimiento de la } \\
\text { búsqueda de alcohol bajo estrés en ratas }\end{array}$ & $\begin{array}{l}\text { El input excitatorio de las neuronas } \\
\text { orexinérgicas a las del NI contribuye } \\
\text { al restablecimiento de la búsqueda } \\
\text { de alcohol }\end{array}$ \\
\hline $\begin{array}{l}\text { Walker } \\
\text { et al [80] }\end{array}$ & $\begin{array}{l}\text { Inyecciones bilaterales en el } \mathrm{NI} \text { de un } \\
\text { agonista del receptor CRF1 o un antagonista } \\
\text { del receptor CRF2 en ratas para inducir el } \\
\text { restablecimiento de la búsqueda de alcohol }\end{array}$ & $\begin{array}{l}\text { Las neuronas del NI contribuyen al } \\
\text { restablecimiento de la búsqueda de } \\
\text { alcohol a través de la señalización de CRF1 }\end{array}$ \\
\hline $\begin{array}{l}\text { Ryan } \\
\text { et al }[54]\end{array}$ & $\begin{array}{l}\text { Modelo de consumo y } \\
\text { búsqueda de alcohol en ratas }\end{array}$ & $\begin{array}{l}\text { La administración central del antagonista } \\
\text { reduce la autoadministración del alcohol } \\
\text { junto con su restablecimiento debido al estrés }\end{array}$ \\
\hline $\begin{array}{l}\text { Ganella } \\
\text { et al [59] }\end{array}$ & $\begin{array}{l}\text { Inyecciones intrahipotalámicas } \\
\text { durante el consumo diario de } \\
\text { comida en ratas macho adultas }\end{array}$ & $\begin{array}{l}\text { La activación crónica de RXFP3 incrementa } \\
\text { la ingesta y la ganancia de peso }\end{array}$ \\
\hline $\begin{array}{l}\text { Ryan } \\
\text { et al [63] }\end{array}$ & $\begin{array}{l}\text { Consumo voluntario de } \\
\text { alcohol en ratas macho }\end{array}$ & $\begin{array}{l}\text { Elevada expresión endógena de RLN3 asociada } \\
\text { con el consumo de sustancias reforzadoras }\end{array}$ \\
\hline $\begin{array}{l}\text { Shirahase } \\
\text { et al [68] }\end{array}$ & $\begin{array}{l}\text { Modelo de consumo de alcohol en } \\
\text { ratones knockout y administración } \\
\text { de un antagonista para el RXFP3 }\end{array}$ & $\begin{array}{l}\text { El sistema neural de RLN3 afecta al } \\
\text { consumo y a la preferencia por el alcohol }\end{array}$ \\
\hline $\begin{array}{l}\text { Haidar } \\
\text { et al }[70]\end{array}$ & $\begin{array}{l}\text { Modelo de consumo escalado } \\
\text { de metanfetamina en ratones } \\
\text { knockout para RLN3 y el receptor }\end{array}$ & $\begin{array}{l}\text { La deficiente señalización endógena de } \\
\text { RLN3 y su receptor no altera la sensibilidad } \\
\text { tras un consumo crónico de metanfetamina }\end{array}$ \\
\hline $\begin{array}{l}\text { Walker } \\
\text { et al [57] }\end{array}$ & $\begin{array}{l}\text { Modelo de consumo de alcohol } \\
\text { como respuesta a la ansiedad } \\
\text { inducida mediante yohimbina }\end{array}$ & $\begin{array}{l}\text { Disminución del restablecimiento } \\
\text { de la búsqueda de alcohol tras inyectar } \\
\text { bilateralmente en el núcleo central de la } \\
\text { amígdala un antagonista selectivo para RXFP3 }\end{array}$ \\
\hline
\end{tabular}

CRF: factor liberador de corticotropina; NI: núcleo incertus; OX: receptor de orexina; RLN3: neuropéptido relaxina-3; RXFP3: receptor de RLN3. pótesis de que los niveles de RLN3 en el NI pueden regular la ingesta voluntaria de sustancias gratificantes. Los niveles de ARNm de RLN3 no fueron notablemente elevados o disminuidos por el consumo crónico de alcohol, sino más bien predispuestos en las ratas a consumir alcohol.

Las sustancias de abuso tienden a ejercer sus principales efectos directamente sobre las vías de recompensa del cerebro, mientras que los alimentos apetecibles tienden a afectar a múltiples vías periféricas y centrales, transmitiendo información a las vías de recompensa del cerebro tanto directa como indirectamente. En el núcleo supraóptico hipotalámico y el núcleo paraventricular se produce una marcada disminución del número de neuronas activas tras una ingesta crónica de alcohol (que se atribuye a la muerte celular), pero las neuronas que sobreviven sufren un proceso de hipertrofia y aumentan su volumen (se ha visto que el tamaño total de núcleo paraventricular, pero no del núcleo supraóptico, se correlaciona con la ingesta de alcohol) [67].

El núcleo de la estría terminal es de particular interés ya que se ha identificado como un locus anatómico donde la señalización de RXFP3 modula la búsqueda de alcohol inducida por el estrés [7], aunque datos actuales sugieren que la ingesta crónica de alcohol no parece regular marcadamente la expresión de RXFP3 [63]. Consistente con esta observación, ratones knockout para el gen de RLN3 aumentan el consumo de alcohol frente al tipo salvaje [68].

El alcohol tiene efectos ansiolíticos bien establecidos en humanos y roedores, lo que proporciona apoyo para una hipótesis de 'reducción del estrés' con el consumo de alcohol en ciertas circunstancias. Se ha estudiado la exposición repetida al estrés del test de inmovilización seguido por dos sesiones de estrés con el test de la natación forzada [69]. La exposición aguda y subcrónica al estrés durante la adicción al alcohol potencia el consumo y la recaída de alcohol en los roedores. La preferencia por el alcohol se reduce significativamente en los ratones knockout para RXFP3 hacia el final del período de exposición al estrés, por lo que este efecto podría deberse a una interacción específica de la señalización de RLN3/RXFP3 con el estrés. De esta forma, en los ratones, la señalización de RLN3/RXFP3 está implicada en el mantenimiento de una alta preferencia por el alcohol durante y después de las situaciones estresantes, pero no parece regular fuertemente el refuerzo primario del alcohol.

El efecto del sistema sobre la adicción es específico del alcohol. Los mutantes knockout para rxfp3 no están afectados en la adicción a las metanfetaminas, y otros tipos de adicción, como a los opiá- 
ceos, no se han explorado [70]. Por otra parte, el sistema NI-RLN3-RXFP3 podría afectar a un mecanismo común a varios tipos de adicción, como la preferencia de lugar condicionada. Este elemento es común a la mayor parte de drogodependencias y consiste en la preferencia de un animal por situarse en el mismo lugar donde recibe las recompensas. El NI, a través de sus conexiones con el hipocampo y el septo [28,71,72], es capaz de modular el ritmo theta hipocámpico [73,74]. El ritmo theta es uno de los elementos electrofisiológicos que concurren en la formación de los mapas espaciales [75]. Por lo tanto, el sistema podría constituir un elemento de configuración del mapa espacial que subyace a la preferencia de lugar condicionada.

La señalización del sistema RLN3/RXFP3 es capaz de influir en la recaída en la ingesta de alcohol en estados de ansiedad. En efecto, la inyección de yohimbina induce el aumento de la expresión de c-Fos en la amígdala central. La inyección ahí de un antagonista de RXFP3 atenúa tal recaída [57]. Del mismo modo, la inyección de un antagonista del receptor de orexina $\mathrm{OX}_{2}$ atenuó la recaída en el consumo de alcohol inducida por yohimbina [76].

\section{Conclusiones}

El proceso de formación de hábitos de conducta, con la puesta en marcha de los mecanismos que constituyen el sustrato neurobiológico del aprendizaje, es fundamental en todos los tipos de adicción. En las adicciones no químicas, como el juego patológico o las compras compulsivas, en las cuales no existen los efectos dopaminérgicos adicionales que la sustancia genera, la activación de los mecanismos neurobiológicos propios del aprendizaje motivacional y del aprendizaje de hábitos debe desempeñar un papel fundamental en el control de la conducta del adicto. Además, los efectos profundos de este tipo de aprendizajes, que forman parte de los mecanismos de memoria procedimental, pueden contribuir a explicar la resistencia a la extinción de las conductas adictivas. Extensas regiones cerebrales, entre las que destacan el VTA, la amígdala, el estriado ventral y dorsal, y la corteza prefrontal, se han implicado en la recaída crónica en el consumo y son el blanco del desarrollo de tratamientos eficaces para el trastorno adictivo. A esta red de centros hay que añadir el NI y su sistema de señalización a través del neuropéptido RLN3, junto con su receptor RXFP3. En todos estos centros se desarrollan cambios neuroadaptativos que incluyen procesos neurobiológicos de aprendizaje y memoria [39].
Existen importantes similitudes entre la bulimia nerviosa y la enfermedad adictiva. Tal paralelismo se hace evidente cuando se comparan los efectos motivacionales de los alimentos sabrosos y las sustancias psicoactivas [77]. En general, las sustancias adictivas tienen efectos más potentes que los alimentos; sin embargo, las neuroadaptaciones propias de la adicción en el sistema de recompensa contribuyen a la hiperfagia hedónica, lo que probablemente conduzca a la obesidad y otros trastornos crónicos [78].

Los eventos estresantes están causalmente vinculados con los trastornos de consumo de alcohol, proporcionando apoyo a la hipótesis de que el consumo de alcohol está dirigido a la reducción del estrés. La demostración de que la expresión del ARNm de RLN3 en el NI del cerebro de rata se correlaciona con la ingesta de alcohol y que el antagonismo central de RXFP3 previene la reincidencia inducida por el estrés de la búsqueda de alcohol implica el papel modulador del estrés del NI en el consumo de sustancias psicoactivas.

Conociendo que el bloqueo de $\mathrm{CRF}_{1}$ atenúa el consumo de alcohol, los estudios farmacológicos comienzan a desvelar un papel para los receptores de CRF dentro de las vías de recompensa del cerebro. Además, los diferentes mecanismos de CRF y las vías pueden reclutarse durante el aumento de la ingesta alcohólica o la ansiedad relacionada con la abstinencia de alcohol [79], lo que da lugar a un camino interesante para la investigación sobre adicción. Mientras que los efectos del alcohol sobre el eje hipotálamo-hipófiso-adrenal, la amígdala y otras estructuras relacionadas con el estrés se han caracterizado más ampliamente, comienzan a surgir contribuciones prometedoras de la señalización de CRF en las vías de recompensa del cerebro. El hecho de la respuesta de las neuronas del NI a la activación de los receptores $\mathrm{CRF}_{1}$ y de las proyecciones del NI a zonas que producen y liberan CRF apuntala la visión de una importante interrelación entre ambos sistemas, que en el caso de la ingesta es de tipo antagónico. Otras patologías psiquiátricas, como los trastornos de la alimentación, presentan puntos en común con la adicción y son un buen modelo de estudio comparativo (Fig. 2).

Por lo tanto, el sistema RLN3/RXFP3 actuaría modulando las conductas adictivas a través de los mecanismos de estrés, reduciendo el arousal y disminuyendo la búsqueda de la sustancia psicoactiva. Se necesitan nuevos estudios para comprender cómo los procesos de recompensa están afectados por el sistema CRF/RLN3 y cómo la actuación sobre esos sistemas puede constituir una nueva herramienta te- 
rapéutica en el tratamiento de las enfermedades adictivas y de trastorno de las conductas alimentarias.

\section{Bibliografía}

1. Pereira T. Neurobiología de la adicción. Revista de Psiquiatría del Uruguay 2009; 73: 9-24.

2. Infante C, Barrio G, Martín E. Tendencias, características y problemas asociados al consumo de drogas recreativas en España. Adicciones 2003; 15: 77.

3. Berridge KC, Kringelbach ML. Pleasure systems in the brain. Neuron 2015; 86: 646-64.

4. Carlezon WA, Thomas MJ. Biological substrates of reward and aversion: a nucleus accumbens activity hypothesis. Neuropharmacology 2009; 56 (Suppl 1): S122-32.

5. Alavi SS, Ferdosi M, Jannatifard F, Eslami M, Alaghemandan H, Setare M. Behavioral addiction versus substance addiction: correspondence of psychiatric and psychological views. Int J Prev Med 2012; 3: 290-4.

6. Koob GF. Theoretical frameworks and mechanistic aspects of alcohol addiction: alcohol addiction as a reward deficit disorder. Curr Top Behav Neurosci 2013; 13: 3-30.

7. Ryan PJ, Kastman HE, Krstew EV, Rosengren KJ, Hossain MA, Churilov L, et al. Relaxin-3/RXFP3 system regulates alcoholseeking. Proc Natl Acad Sci U S A 2013; 110: 20789-94.

8. Ma S, Sang Q, Lanciego JL, Gundlach AL. Localization of relaxin-3 in brain of Macaca fascicularis: identification of a nucleus incertus in primate. J Comp Neurol 2009; 517: 856-72.

9. Tanaka M, Iijima N, Miyamoto Y, Fukusumi S, Itoh Y, Ozawa H, et al. Neurons expressing relaxin 3/INSL 7 in the nucleus incertus respond to stress. Eur J Neurosci 2005; 21: 1659-70.

10. Liu C, Eriste E, Sutton S, Chen J, Roland B, Kuei C, et al. Identification of relaxin-3/INSL7 as an endogenous ligand for the orphan g-protein-coupled receptor GPCR135. J Biol Chem 2003; 278: 50754-64.

11. McClelland J, Bozhilova N, Campbell I, Schmidt U. A systematic review of the effects of neuromodulation on eating and body weight: evidence from human and animal studies. Eur Eat Disord Rev 2013; 21: 436-55.

12. Piccoli L, Micioni Di Bonaventura MV, Cifani C, Costantini VJA, Massagrande M, Montanari D, et al. Role of orexin-1 receptor mechanisms on compulsive food consumption in a model of binge eating in female rats. Neuropsychopharmacology 2012; 37: 1999-2011.

13. American Psychiatric Association. Diagnostic and statistical manual of mental disorders, fifth edition (DSM-5). Washington DC: APA; 2013

14. Calvez J, De Ávila C, Matte LO, Guèvremont G, Gundlach AL Timofeeva E. Role of relaxin-3/RXFP3 system in stress-induced binge-like eating in female rats. Neuropharmacology 2016; 102: 207-15.

15. Munro J, Skrobot O, Sanyoura M, Kay V, Susce MT, Glaser PE, et al. Relaxin polymorphisms associated with metabolic disturbance in patients treated with antipsychotics. J Psychopharmacol 2012; 26: 374-9.

16. Santos FN, Pereira CW, Sánchez-Pérez AM, Otero-García M, Ma S, Gundlach AL, et al. Comparative distribution of relaxin-3 inputs and calcium-binding protein-positive neurons in rat amygdala. Front Neuroanat 2016; 10: 36.

17. Petsche H, Stumpf C, Gogolak G. The significance of the rabbit's septum as a relay station between the midbrain and the hippocampus. I. The control of hippocampus arousal activity by the septum cells. Electroencephalogr Clin Neurophysiol 1962; 14: 202-11.

18. Miyamoto Y, Watanabe $Y$, Tanaka M. Developmental expression and serotonergic regulation of relaxin 3/INSL7 in the nucleus incertus of rat brain. Regul Pept 2008; 145: 54-9.

19. Ma S, Gundlach AL. Ascending control of arousal and motivation: role of nucleus incertus and its peptide neuromodulators in behavioural responses to stress. J Neuroendocrinol 2015; 27: 457-67.

20. Ma S, Allocca G, Ong-Pålsson EKE, Singleton CE, Hawkes D,
McDougall SJ, et al. Nucleus incertus promotes cortical desynchronization and behavioral arousal. Brain Struct Funct 2017; 222: 515-37.

21. España RA, Schmeichel BE, Berridge CW. Norepinephrine at the nexus of arousal, motivation and relapse. Brain Res 2016; 1641: 207-16.

22. Liu C, Chen J, Sutton S, Roland B, Kuei C, Farmer N, et al. Identification of relaxin-3/INSL7 as a ligand for GPCR142. J Biol Chem 2003; 278: 50765-70.

23. Smith CM, Ryan PJ, Hosken IT, Ma S, Gundlach AL. Relaxin-3 systems in the brain -the first 10 years. J Chem Neuroanat 2011; 42: 262-75.

24. Smith CM, Lawrence AJ, Sutton SW, Gundlach AL. Behavioral phenotyping of mixed background (129S5:B6) relaxin-3 knockout mice. Ann N Y Acad Sci 2009; 1160: 236-41.

25. Bathgate RA, Samuel CS, Burazin TC, Layfield S, Claasz AA, Reytomas IG, et al. Human relaxin gene 3 (H3) and the equivalent mouse relaxin (M3) gene. Novel members of the relaxin peptide family. J Biol Chem 2002; 277: 1148-57.

26. Silvertown JD, Neschadim A, Liu HN, Shannon P, Walia JS, Kao JC, et al. Relaxin-3 and receptors in the human and rhesus brain and reproductive tissues. Regul Pept 2010; 159: 44-53.

27. Goto M, Swanson LW, Canteras NS. Connections of the nucleus incertus. J Comp Neurol 2001; 438: 86-122.

28. Olucha-Bordonau FE, Terue, V, Barcia-González J, RuizTorner A, Valverde-Navarro AA, Martínez-Soriano F, et al. Cytoarchitecture and efferent projections of the nucleus incertus of the rat. J Comp Neurol 2003; 464: 62-97.

29. Donizetti A, Fiengo M, Minucci S, Aniello F. Duplicated zebrafish relaxin-3 gene shows a different expression pattern from that of the co-orthologue gene. Dev Growth Differ 2009; 51: 715-22.

30. Banerjee A, Shen PJ, Ma S, Bathgate RA, Gundlach AL. Swim stress excitation of nucleus incertus and rapid induction of relaxin-3 expression via CRF1 activation. Neuropharmacology 2010; 58: 145-55.

31. Nategh M, Nikseresht S, Khodagholi F, Motamedi F. Nucleus incertus inactivation impairs spatial learning and memory in rats. Physiol Behav 2015; 139: 112-20.

32. Nategh M, Nikseresht S, Khodagholi F, Motamedi F. Inactivation of nucleus incertus impairs passive avoidance learning and long term potentiation of the population spike in the perforant path-dentate gyrus evoked field potentials in rats. Neurobiol Learn Mem 2016; 130: 185-93.

33. Haidar $M$, Guèvremont $G$, Zhang $C$, Bathgate RA, Timofeeva $E$, Smith CM, et al. Relaxin-3 inputs target hippocampal interneurons and deletion of hilar relaxin-3 receptors in 'floxedRXFP3' mice impairs spatial memory. Hippocampus 2017; 27: 529-46.

34. Pereira CW, Santos FN, Sánchez-Pérez AM, Otero-García M, Marchioro M, Ma S, et al. Electrolytic lesion of the nucleus incertus retards extinction of auditory conditioned fear. Behav Brain Res 2013; 247: 201-10.

35. Kania A, Gugula A, Grabowiecka A, De Ávila C, Blasiak T, Rajfu, Z, et al. Inhibition of oxytocin and vasopressin neuron activity in rat hypothalamic paraventricular nucleus by relaxin-3-RXFP3 signalling. J Physiol 2017; 595: 3425-47.

36. Ma S, Blasiak A, Olucha-Bordonau FE, Verberne AJM, Gundlach AL. Heterogeneous responses of nucleus incertus neurons to corticotrophin-releasing factor and coherent activity with hippocampal theta rhythm in the rat. J Physiol 2013; 591: 3981-4001.

37. Greco MA, Shiromani PJ. Hypocretin receptor protein and mRNA expression in the dorsolateral pons of rats. Brain Res Mol Brain Res 2001; 88: 176-82.

38. Kumar JR, Rajkumar R, Jayakody T, Marwari S, Hong JM, Ma S, et al. Relaxin' the brain: a case for targeting the nucleus incertus network and relaxin-3/RXFP3 system in neuropsychiatric disorders. Br J Pharmacol 2017; 174: 1061-76.

39. Corominas-Roso M, Roncero C, Bruguera E, Casas M. Sistema dopaminérgico y adicciones. Rev Neurol 2007; 44: 23-31.

40. Van der Broek-Stice L, Stojek MK, Beach SR, Van Dellen MR, MacKillop J. Multidimensional assessment of impulsivity in 
relation to obesity and food addiction. Appetite 2017; 112: 59-68.

41. Pedrero-Pérez EJ, coord. Neurociencia y adicción. Valencia: Sociedad Española de Toxicomanías; 2011.

42. Settell ML, Testini P, Cho S, Lee JH, Blaha CD, Jo HJ, et al. Functional circuitry effect of ventral tegmental area deep brain stimulation: imaging and neurochemical evidence of mesocortical and mesolimbic pathway modulation. Front Neurosci 2017; 11: 104

43. Ruan H, Yao WD. Cocaine promotes coincidence detection and lowers induction threshold during hebbian associative synaptic potentiation in prefrontal cortex. J Neurosci 2017; 37: 986-97.

44. Farooq U, Rajkumar R, Sukumaran S, Wu Y, Tan WH, Dawe GS. Corticotropin-releasing factor infusion into nucleus incertus suppresses medial prefrontal cortical activity and hippocampo-medial prefrontal cortical long-term potentiation. Eur J Neurosci 2013; 38: 2516-25.

45. Matsumoto M, Hikosaka O. Lateral habenula as a source of negative reward signals in dopamine neurons. Nature 2007; 447: 1111-5.

46. Salaberry NL, Mendoza J. Insights into the role of the habenular circadian clock in addiction. Front Psychiatry 2016; 6: 179.

47. Baker PM, Jhou T, Li B, Matsumoto M, Mizumori SJ, StephensonJones $\mathrm{M}$, et al. The lateral habenula circuitry: reward processing and cognitive control. J Neurosci 2016; 36: 11482-8.

48. Haack AK, Sheth C, Schwager AL, Sinclair MS, Tandon S, Taha SA. Lesions of the lateral habenula increase voluntary ethanol consumption and operant self-administration, block yohimbine-induced reinstatement of ethanol seeking, and attenuate ethanol-induced conditioned taste aversion. PLoS One 2014; 9: e92701.

49. Smith CM, Hosken IT, Sutton SW, Lawrence AJ, Gundlach AL. Relaxin-3 null mutation mice display a circadian hypoactivity phenotype. Genes Brain Behav 2012; 11: 94-104.

50. Bittencourt JC, Sawchenko PE. Do centrally administered neuropeptides access cognate receptors?: an analysis in the central corticotropin-releasing factor system. J Neurosci 2000; 20: 1142-56.

51. Blasiak A, Gundlach AL, Hess G, Lewandowski MH. Interactions of circadian rhythmicity, stress and orexigenic neuropeptide systems: implications for food intake control. Front Neurosci 2017; 11: 127

52. Singewald N, Salchner P, Sharp T. Induction of c-Fos expression in specific areas of the fear circuitry in rat forebrain by anxiogenic drugs. Biol Psychiatry 2003; 53: 275-83.

53. Watanabe Y, Tsujimura A, Takao K, Nishi K, Ito Y, Yasuhara Y, et al. Relaxin-3-deficient mice showed slight alteration in anxiety-related behavior. Front Behav Neurosci 2011; 5: 50.

54. Ryan PJ, Buchler E, Shabanpoor F, Hossain MA, Wade ID, Lawrence AJ, et al. Central relaxin-3 receptor (RXFP3) activation decreases anxiety- and depressive-like behaviours in the rat. Behav Brain Res 2013; 244: 142-51.

55. Kumar JR, Rajkumar R, Lee LC, Dawe GS. Nucleus incertus contributes to an anxiogenic effect of buspirone in rats: involvement of 5-HT1A receptors. Neuropharmacology 2016; 110: 1-14

56. Lüthi A, Lüscher C. Pathological circuit function underlying addiction and anxiety disorders. Nat Neurosci 2014; 17: 1635-43.

57. Walker LC, Kastman HE, Krstew EV, Gundlach AL, Lawrence AJ. Central amygdala relaxin-3/relaxin family peptide receptor 3 signalling modulates alcohol seeking in rats. $\mathrm{Br} \mathrm{J}$ Pharmacol 2017; 174: 3359-69.

58. Wolz I, Granero R, Fernández-Aranda F. A comprehensive model of food addiction in patients with binge-eating symptomatology: the essential role of negative urgency. Compr Psychiatry 2017; 74: 118-24.

59. Ganella DE, Callander GE, Ma S, Bye CR, Gundlach AL, Bathgate RA. Modulation of feeding by chronic rAAV expression of a relaxin-3 peptide agonist in rat hypothalamus. Gene Ther 2013; 20: 703-16.
60. Lenglos C, Mitra A, Guevremont G, Timofeeva E. Sex differences in the effects of chronic stress and food restriction on body weight gain and brain expression of CRF and relaxin-3 in rats. Genes Brain Behav 2013; 12: 370-87.

61. Calvez J, De Ávila C, Timofeeva E. Sex-specific effects of relaxin-3 on food intake and body weight gain. $\mathrm{Br} J$ Pharmacol 2017; 174: 1049-60.

62. Lenglos C, Mitra A, Guèvremont G, Timofeeva E. Regulation of expression of relaxin-3 and its receptor RXFP3 in the brain of diet-induced obese rats. Neuropeptides 2014; 48: 119-32.

63. Ryan PJ, Krstew EV, Sarwar M, Gundlach AL, Lawrence AJ. Relaxin-3 mRNA levels in nucleus incertus correlate with alcohol and sucrose intake in rats. Drug Alcohol Depend 2014; 140: 8-16.

64. Heilig M, Koob GF. A key role for corticotropin-releasing factor in alcohol dependence. Trends Neurosci 2007; 30: 399-406.

65. Quadros IM, Macedo GC, Domingues LP, Favoretto CA. An update on CRF mechanisms underlying alcohol use disorders and dependence. Front Endocrinol (Lausanne) 2016; 7: 134.

66. Hwa LS, DeBold JF, Miczek KA. Alcohol in excess: CRF1 receptors in the rat and mouse VTA and DRN. Psychopharmacology (Berl) 2013; 225: 313-27.

67. Silva SM, Madeira MD, Ruela C, Paula-Barbosa MM. Prolonged alcohol intake leads to irreversible loss of vasopressin and oxytocin neurons in the paraventricular nucleus of the hypothalamus. Brain Res 2002; 925: 76-88.

68. Shirahase T, Aoki M, Watanabe R, Watanabe Y, Tanaka M. Increased alcohol consumption in relaxin-3 deficient male mice. Neurosci Lett 2016; 612: 155-60.

69. Walker AW, Smith CM, Chua BE, Krstew EV, Zhang C, Gundlach AL, et al. Relaxin-3 receptor (RXFP3) signalling mediates stress-related alcohol preference in mice. PLoS One 2015; 10: e0122504.

70. Haidar M, Lam M, Chua BE, Smith CM, Gundlach AL. Sensitivity to chronic methamphetamine administration and withdrawal in mice with relaxin-3/RXFP3 deficiency. Neurochem Res 2016; 41: 481-91.

71. Sánchez-Pérez AM, Arnal-Vicente I, Santos FN, Pereira CW, El Mlili N, Sanjuán J, et al. Septal projections to the nucleus incertus in the rat: bidirectional pathways for modulation of hippocampal function. J Comp Neurol 2015; 523: 565-88.

72. Albert-Gascó H, Ma S, Ros-Bernal F, Sánchez-Pérez AM, Gundlach AL, Olucha-Bordonau FE. GABAergic neurons in the rat medial septal complex express relaxin-3 receptor (RXFP3) mRNA. Front Neuroanat 2018; 11: 133.

73. Núñez A, Cervera-Ferri A, Olucha-Bordonau FE, Ruiz-Torner A, Teruel V. Nucleus incertus contribution to hippocampal theta rhythm generation. Eur J Neurosci 2006; 23: 2731-8.

74. Ma S, Olucha-Bordonau FE, Hossain A, Lin F, Kuei C, Liu C, et al. Modulation of hippocampal theta oscillations and spatial memory by relaxin- 3 neurons of the nucleus incertus. Learn Mem 2009; 16: 730-42.

75. O'Keefe J. Hippocampus, theta, and spatial memory. Curr Opin Neurobiol 1993; 3: 917-24.

76. Kastman HE, Blasiak A, Walker L, Siwiec M, Krstew EV, Gundlach AL, et al. Nucleus incertus orexin2 receptors mediate alcohol seeking in rats. Neuropharmacology 2016; 110: 82-91.

77. Rogers PJ. Food and drug addictions: similarities and differences. Pharmacol Biochem Behav 2017; 153: 182-90.

78. Wiss DA, Criscitelli K, Gold M, Avena N. Preclinical evidence for the addiction potential of highly palatable foods: current developments related to maternal influence. Appetite 2016; 115: 19-27.

79. Knapp DJ, Overstreet DH, Huang M, Wills TA, Whitman BA, Angel RA, et al. Effects of a stressor and corticotrophin releasing factor on ethanol deprivation-induced ethanol intake and anxiety-like behavior in alcohol-preferring P rats. Psychopharmacology (Berl) 2011; 218: 179-89.

80. Walker LC, Kastman HE, Koeleman JA, Smith CM, Perry CJ, Krstew EV, et al. Nucleus incertus corticotrophin-releasing factor 1 receptor signalling regulates alcohol seeking in rats. Addict Biol 2016; 22: 1641-54. 
A new agent in the mechanisms underlying addiction and ingestion of alcohol: the nucleus incertus and the neuropeptide relaxin-3

Summary. Alcohol intake is facilitated by its relationship with eating behavior and both processes are highly influenced by situations of stress and anxiety. The dysregulation of these processes can reach pathological situations such as anorexia, bulimia or obesity. The neurobiological elements which underlie this control are not completely clarified. The nucleus incertus (NI) in the pontine tegmentum is a common element in the food intake and alcoholism. $\mathrm{NI}$ is characterized by using the neuropeptide relaxin-3 (RLN3) as transmitter and its receptor RXFP3. In the present review, we will analyze the participation of the NI-RLN3-RXFP3 system in these behaviors under conditions of anxiety or stress in animal models. The activation of $\mathrm{NI}$ has a positive effect on intake (orexigenic) and generates a wide response in the amygdala modulating anxiety states. The activity of RLN3-RXFP3 in the amygdala could affect alcohol addiction since the application of the RXFP3 antagonist in extended amygdala attenuates the relapse to alcohol induced by stress. The neuroanatomical data indicate that the NI-RLN3-RXFP3 system acts on the feeding behavior and alcohol intake by means of projections parallel to the canonical mesolimbic pathways. Thus, data in animal models indicate that the NI-RLN3-RXFP3 system should be taken into account as a target in the future treatment of disorders of eating and alcohol addictive behaviors.

Key words. Alcoholism. Anorexia. Anxiety. Arousal. Bulimia. Stress. 